\title{
Factors related to the risk of illness of nursing staff at work in a psychiatric institution*
}

\author{
Kayo Henrique Jardel Feitosa Sousa $a^{1,2}$ \\ (1) https://orcid.org/0000-0002-0901-7752 \\ Regina Célia Gollner Zeitoune ${ }^{1}$ \\ (1D) https://orcid.org/0000-0002-0276-8166 \\ Luciana Fernandes Portela ${ }^{3}$ \\ (1) https://orcid.org/0000-0001-8961-468X \\ Gisele Massante Peixoto Tracera ${ }^{4}$ \\ (1D) https://orcid.org/0000-0001-9896-9191 \\ Katerine Gonçalves Moraes ${ }^{4}$ \\ (ID) https://orcid.org/0000-0002-2064-5207 \\ Rachel Ferreira Savary Figueiró 1 \\ (D) https://orcid.org/0000-0003-1470-7616
}

Objective: identify the associations between the sociodemographic, and work variables, health conditions and lifestyles, and the risks of illness of nursing workers in a psychiatric hospital. Method: analytical cross-sectional study. The sample of 74 workers answered a questionnaire for sociodemographic, work, health conditions and lifestyles survey characterization. The Work Context Assessment Scale and the Human Cost at Work Scale were used to evaluate the perception of the risks of illness in the interviewee's opinion. A descriptive and bivariate analysis was performed, with significance of $5 \%$. Results: the factors associated with the risk of illness were: insomnia complaints, night work and workday. Conclusion: the associations between the work variables, health conditions and life habits can harm the health of the nursing staff of a psychiatric hospital.

Descriptors: Working Conditions; Psychiatric Nursing; Nursing, Team; Hospitals, Psychiatric; Mental Health; Occupational Health.

\section{How to cite this article}

Sousa KHJF, Zeitoune RCG, Portela LF, Tracera GMP, Moraes KG, Figueiró RFS. Factors related to the risk of illness of nursing staff at work in a psychiatric institution. Rev. Latino-Am. Enfermagem. 2020;28:e3235. [Access †f一_]; Available in: DOI: http://dx.doi.org/10.1590/1518-8345.3454.3235. month day year 


\section{Introduction}

The Psychiatric Reform was a milestone in mental health care in Brazil. Since then, many advances can be observed in the care and management of these services, considering the processes of deinstitutionalization and dehospitalization of users, with reorientation of the psychiatric care model(1). However, areas of care gaps and the need of "replacement of the mental hospitals still operating in Brazil"(2), in line with the principle of universal coverage of mental health in the country, with emphasis on regions with low economic development.

In this context, mental health services produce situations that affect health conditions, in particular, of nursing professionals. These situations increase the risks of illness associated with the feeling of physical fatigue at the end of the work day, caused by the fear of suffering some kind of aggression by users ${ }^{(3)}$, exposure to physical and psychic loads, inadequate working conditions, limitation of autonomy, stress complaints, body aches, anxiety and fatigue, leading to suffering at work $^{(4)}$.

A research(5) reinforces the occurrence of violence in the context of psychiatry, by identifying a higher prevalence of aggressions by patients to nurses working in psychiatric settings, in addition to presenting a worse subjective state of health and reduced working capacity in relation to those who worked in clinical and surgical units.

Inadequate working conditions and care for people with mental disorders with considerable cognitive demand represent critical risks for the illness of nursing workers ${ }^{(6-7)}$. Night work, a common situation among these workers, is a strong factor of occupational exposure, generating important consequences for the work activity and health conditions of the worker(8-9). In addition, the results of care - sometimes out of reality -, the state of continuous surveillance and professional dissatisfaction related to environmental structure, comfort, safety and wages should potentiate the possibilities of illness ${ }^{(7,10)}$.

The work context requires workers to make use of personal characteristics and physical and mental balance to face the stressful place of work, pressure and responsibilities(11). Added to this scenario is the exposure to the long working days - commonly observed in nursing teams -, associated with Burnout syndrome, dissatisfaction at work, intention to leave the profession and increased patient dissatisfaction ${ }^{(12)}$. Thus, the work carried out in a psychiatric institution exposes health professionals to physical and psychological stress, contributing to the development of several diseases and occupational stress.

It is observed, then, that some characteristics of nursing work expose this professional category to different occupational risks and, particularly, worrisome when considering psychiatric institutions. In view of the context of the Brazilian Psychiatric Reform, the problem of professional insecurity regarding its future is still be seen in the hospital care scenario. The Rede de Atenção Psicossocial (RAPS - Psychosocial Care Network) foresees deinstitutionalization as a guiding principle and an increase in the number of beds in general hospitals, generating uncertainty among professionals in psychiatric hospitals regarding their insertion in this work process.

Considering the above, the objective of this research was to identify the associations between the sociodemographic, work, health conditions and lifestyle variables and the risks of illness of nursing workers in a psychiatric hospital.

\section{Method}

This is an analytical cross-sectional study, developed in the period from March to April 2016, in a public psychiatric hospital in the Northeast region of Brazil. The hospital - which receives patients from all over the state and several states in the North and Northeast regions - is composed of: Integral Hospitalization Unit with 160 beds divided into male, female, geriatric and clinical pavilions; Anti-Crisis Treatment Unit, with eight beds of attention, four male and four female; Outpatient Service for external care and Emergency Service operating 24 hours a day, with nursing assistance in all the referred units.

The population of this study consisted of 98 nursing professionals working in the psychiatric institution, 18 of them were nurses and 80 nursing technicians/ assistants. Of these, five professionals participated in the pre-test and three were on vacation or on leave and the target population was 90 participants ( 17 nurses and 73 nursing technicians/auxiliaries). The workers who worked in the assistance were considered eligible for the study and those who worked in the administrative area did not provide direct assistance to patients were excluded.

After applying the inclusion and exclusion criteria, the sample was composed of 74 nursing workers, 14 of whom were nurses, 16 nursing assistants and 44 nursing technicians. The final sample of the study represented $82.2 \%$ of the target population. The following losses 
were recorded: eight workers by refusal and eight were not found in the data collection period.

The data collection occurred inside the institution, based on individual interviews, carried out by trained research assistants, five of them undergraduate students in Nursing and one nurse expert in Occupational Nursing. All the assistants received information about the research objectives, methods and techniques, being explained the meanings of the data collection instrument. After the training, the research assistants went to the institution to apply the instrument, programming the schedules for the collection according to the participant's availability.

The collection instrument consisted of a multithematic questionnaire, structured into two blocks of questions.

The first block included questions related to sociodemographic characterization (sex, age, marital status and children), work (professional category, work hours, shift and number of jobs), health conditions with medical diagnosis and life habits (physical activity, leisure and insomnia complaints).

The second block presented the instruments used to assess the risks of illness at work, namely: the Escala de Avaliação do Contexto de Trabalho (EACT) Work Context Evaluation Scale - composed of 31 items divided into three dimensions - work organization, socio-professional relations and working conditions ${ }^{(13)}$ and the Escala de Custo Humano no Trabalho (ECHT) Human Cost at Work Scale - which has 32 items divided into the dimensions - emotional cost, cognitive cost and physical cost ${ }^{(13)}$.

The scales mentioned are part of the Inventário sobre Trabalho e Risco de Adoecimento (ITRA) Inventory about Work and Illness Risk -, a public domain instrument developed in 2003 and validated in 2004 and $2006^{(13)}$.

These scales evaluate the risk of illness in the employee's opinion. To each question is assigned a score ranging from 1 to 5 , depending on the intensity of the risk. In other words, the higher the score, the more noticeable the risk, and the final score is obtained by the arithmetic mean of each question, subsequently grouped to form the dimensions of risk of illness. According to the authors of the scales mentioned above, when the score is lower than 2.29, the work environment does not offer risk to the worker; between 2.3 and 3.69, the work environment offers moderate risk; and higher than 3.7, serious risk for worker illness(13). In this study, in order to maximize the differences between the groups, the classifications were reduced from three to two groups - with risk of illness (score $\geq 2.3$ ) and without risk of illness (score $<2.3$ ).

The data were analyzed with the help of the Statistical Package for the Social Sciences (SPSS) version 21.0. Frequency distribution tables were used to analyze the variables. For bivariate analyses, Pearson's chisquare test or Fisher's exact test were used, adopting a statistical significance level of $5 \%$. The estimation of the Odds Ratio (OR) was also evaluated, with a respective confidence interval of $95 \%(95 \% \mathrm{CI})$. The reliability of the scales was evaluated using Cronbach's alpha coefficient, showing good internal consistency of the set of items that make up the risk factors for illness, ranging from 0.561 to 0.905 .

The study was referred to the Research Ethics Committee under CAAE no. 52679216.7.0000.5238, obtaining a favorable report no. 1.434.109. It development complied the ethical precepts of Resolution no. 466/2012 of the National Health Council. Data collection was only initiated after all doubts of the participants were solved and the Informed Consent Form was signed.

\section{Results}

$74(82.2 \%)$ workers participated in the study, predominantly female $(91.9 \%)$, without a partner $(54.1 \%)$, without children under 6 years of age $(87.8 \%)$, in the age range between 48 and 72 years (59.5\%), with an average of $49( \pm 9.22)$ years. Regarding the characteristics related to work, there was a predominance of professionals who worked up to 30 hours a week $(70.3 \%)$, with only one job (54.1\%) and performed their activities during the night (56.8\%). Regarding health conditions and life habits, most participants reported practicing physical activity (56.8\%), having time for leisure $(78.4 \%)$, having at least three health problems diagnosed by a medical professional (74.3\%) and not suffering of insomnia (66.2\%).

According to the results presented in Table 1 , it was possible to observe that insomnia complaints were more frequent among workers at risk of illness for socio-professional relationships. Workers at risk of illness for personal relationships are 4.22 (CI: 1.43-12.41) times more likely to report insomnia complaints. In relation to working hours, we noted its association with both the risk of illness for work organization and working conditions. Although no significant associations were observed with regard to the analysis of the odds ratio, a greater proportion of the risks of illness was observed among workers who work longer than 30 hours per week. 
Table 1 - Association between the risk of illness, evaluated by the dimensions of work organization, socio-professional relations, working conditions and the sociodemographic, work and related to health and lifestyle variables in nursing workers of a psychiatric hospital, Northeast region of Brazil, $2016(n=74)$

\begin{tabular}{|c|c|c|c|c|c|c|c|c|c|c|}
\hline \multirow{3}{*}{ Variable } & \multirow{3}{*}{$\mathbf{n}$} & \multicolumn{9}{|c|}{ IIIness Risk } \\
\hline & & \multicolumn{3}{|c|}{ Work organization } & \multicolumn{3}{|c|}{ Socio-professional relations } & \multicolumn{3}{|c|}{ Working conditions } \\
\hline & & $\mathrm{n}(\%)$ & $\mathrm{OR}^{*}\left(95 \% \mathrm{IC}^{\dagger}\right)$ & $\mathbf{p}$ & $(n) \%$ & $\mathrm{OR}^{*}\left(95 \% \mathrm{IC}^{\dagger}\right)$ & $\mathbf{p}$ & $n(\%)$ & $\mathrm{OR}^{\star}\left(95 \% \mathrm{IC}^{\dagger}\right)$ & $\mathbf{p}$ \\
\hline \multicolumn{11}{|l|}{ Sex $x^{\ddagger}$} \\
\hline Male & 06 & $04(66.7)$ & 1.0 & & $04(66.7)$ & 1.0 & & $06(100)$ & - & \\
\hline Female & 68 & $44(64.7)$ & $0.91(0.15-5.37)$ & 0.648 & $36(52.9)$ & $0.56(0.09-3.27)$ & 0.418 & $60(88.2)$ & - & 0.490 \\
\hline \multicolumn{11}{|l|}{ Age Group } \\
\hline 23 to 47 years old & 30 & $20(66.7)$ & 1.0 & & 19(63.3) & 1.0 & & $26(86.7)$ & 1.0 & \\
\hline 48 to 72 years old & 44 & $28(63.6)$ & $0.87(0.33-2.32)$ & 0.789 & $21(47.7)$ & $0.52(0.20-1.36)$ & 0.186 & $40(90.9)$ & $1.53(0.35-6.69)$ & 0.416 \\
\hline \multicolumn{11}{|l|}{ Marital status } \\
\hline No partner & 40 & $29(72.5)$ & 1.0 & & $21(52.5)$ & 1.0 & & $38(95.0)$ & 1.0 & \\
\hline With partner & 34 & 19(55.9) & $0.48(0.18-1.26)$ & 0.136 & 19(55.9) & $1.14(0.45-2.87)$ & 0.771 & $28(82.4)$ & $0.24(0.04-1.30)$ & 0.085 \\
\hline \multicolumn{11}{|l|}{ Children ( $\leq 6$ years) } \\
\hline No & 65 & $43(66.2)$ & 1.0 & & $34(52.3)$ & 1.0 & & $59(90.8)$ & 1,0 & \\
\hline Yes & 09 & $05(55.6)$ & $0.64(0.15-2.62)$ & 0.391 & $06(66.7)$ & $1.82(0.42-7.92)$ & 0.329 & $07(77.8)$ & $0.35(0.06-2.11)$ & 0.249 \\
\hline \multicolumn{11}{|l|}{ Category } \\
\hline Nurse & 14 & $09(64.3)$ & 1.0 & & $06(42.9)$ & 1.0 & & $11(78.6)$ & 1.0 & \\
\hline Assistant/technician & 60 & $39(65.0)$ & $1.03(0.30-3.47)$ & 0.595 & $34(56.7)$ & $1.74(0.53-5.64)$ & 0.351 & $55(91.7)$ & $3.00(0.62-14.43)$ & 0.169 \\
\hline \multicolumn{11}{|l|}{ Work hours ${ }^{\ddagger}$} \\
\hline$\leq 30$ hours per week & 52 & $30(57.7)$ & 1.0 & & $26(50.0)$ & 1.0 & & $44(84.6)$ & - & \\
\hline$>30$ hours per week & 22 & $18(81.8)$ & $3.30(0.97-11.12)$ & 0.047 & 14(63.6) & $1.75(0.62-4.87)$ & 0.282 & $22(100)$ & - & 0.051 \\
\hline \multicolumn{11}{|l|}{ Number of jobs } \\
\hline Just one & 40 & $27(67.5)$ & 1.0 & & $24(60.0)$ & 1.0 & & $38(95.0)$ & 1.0 & \\
\hline Two or more & 34 & $21(61.8)$ & $0.77(0.29-2.02)$ & 0.607 & $16(47.1)$ & $0.59(0.23-1.49)$ & 0.266 & $28(82.4)$ & $0.24(0.04-1.30)$ & 0.085 \\
\hline \multicolumn{11}{|l|}{ Night shift } \\
\hline No & 32 & $20(62.5)$ & 1.0 & & $14(43.8)$ & 1.0 & & $28(87.5)$ & 1.0 & \\
\hline Yes & 42 & $28(66.7)$ & $1.20(0.45-3.13)$ & 0.710 & $26(61.9)$ & $2.08(0.82-5.32)$ & 0.121 & $38(90.5)$ & $1.35(0.31-5.89)$ & 0.683 \\
\hline \multicolumn{11}{|l|}{ Physical activity } \\
\hline Yes & 42 & $29(66.7)$ & 1.0 & & $23(54.8)$ & 1.0 & & $36(85.7)$ & 1.0 & \\
\hline No & 32 & $20(62.5)$ & $0.83(0.31-2.17)$ & 0.710 & $17(53.1)$ & $0.93(0.37-2.35)$ & 0.889 & $30(93.8)$ & $2.50(0.47-13.30)$ & 0.238 \\
\hline \multicolumn{11}{|l|}{ Leisure time } \\
\hline Yes & 58 & $36(62.1)$ & 1.0 & & $31(53.4)$ & 1.0 & & $51(87.9)$ & 1.0 & \\
\hline No & 16 & $12(75.0)$ & $1.83(0.52-6.39)$ & 0.337 & $09(56.3)$ & $1.12(0.36-3.41)$ & 0.842 & 15(93.8) & $2.05(0.23-18.08)$ & 0.507 \\
\hline \multicolumn{11}{|l|}{ Health problems } \\
\hline Three diagnostics & 55 & $36(65.5)$ & 1.0 & & $30(54.5)$ & 1.0 & & 49(89.1) & 1.0 & \\
\hline$\geq 4$ diagnostics & 19 & $12(63.2)$ & $0.90(0.30-2.67)$ & 0.857 & $10(52.6)$ & $0.92(0.32-2.63)$ & 0.885 & $17(89.5)$ & $1.04(0.19-5.65)$ & 0.666 \\
\hline \multicolumn{11}{|l|}{ Insomnia complaints } \\
\hline No & 49 & $30(61.2)$ & 1.0 & & $21(42.9)$ & 1.0 & & $43(87.9)$ & 1.0 & \\
\hline Yes & 25 & $18(72.0)$ & $1.62(0.57-4.63)$ & 0.358 & 19(76.0) & $4.22(1.43-12.41)$ & 0.007 & $23(92.0)$ & $1.60(0.30-8.59)$ & 0.451 \\
\hline
\end{tabular}

*OR = Odds Ratio; ${ }^{+} \mathrm{CI}=$ Confidence interval; ${ }^{\ddagger}$ not possible to calculate the measure of association between the indicated variable and working conditions

The data in Table 2 show that the relationship between the risk of illness and the study variables was expressed in the significant association between physical cost and insomnia complaints. Individuals who reported insomnia complaints are approximately three times more likely to present risk of illness for physical cost at work. A similar result is observed when evaluating the night shift, which is 2.70 (CI: 1.05-6.99) times higher in those with risk of illness. 
Table 2 - Association between the risk of illness, evaluated by the dimensions affective cost, cognitive cost, physical cost and the sociodemographic, labor, and health-related variables and life habits in nursing workers of a psychiatric hospital, Northeast region of Brazil, $2016(n=74)$

\begin{tabular}{|c|c|c|c|c|c|c|c|c|c|c|}
\hline \multirow{3}{*}{ Variable } & \multirow{3}{*}{$\mathbf{n}$} & \multicolumn{9}{|c|}{ Risk of illness } \\
\hline & & \multicolumn{3}{|c|}{ Affective cost } & \multicolumn{3}{|c|}{ Cognitive cost } & \multicolumn{3}{|c|}{ Physical cost } \\
\hline & & $n(\%)$ & $\mathrm{OR}^{*}(95 \% \mathrm{IC}+)$ & $p$ & $(n) \%$ & $\mathrm{OR}^{*}\left(95 \% \mathrm{IC} \mathrm{C}^{\dagger}\right)$ & $p$ & $n(\%)$ & $\mathrm{OR}^{*}\left(95 \% \mathrm{IC} \mathrm{C}^{\dagger}\right)$ & $p$ \\
\hline \multicolumn{11}{|l|}{ Sex } \\
\hline Male & 06 & $03(50.0)$ & 1.0 & & 05(83.3) & 1.0 & & $02(33.3)$ & 1.0 & \\
\hline Female & 68 & $32(47.1)$ & $0.88(0.16-4.72)$ & 0.609 & $54(79.4)$ & $0.77(0.08-7.14)$ & 0.649 & $36(52.9)$ & $2.25(0.38-13.11)$ & 0.311 \\
\hline \multicolumn{11}{|l|}{ Age Group } \\
\hline 23 to 47 years old & 30 & 13(43.3) & 1.0 & & $24(80.0)$ & 1.0 & & $15(50.0)$ & 1.0 & \\
\hline 48 to 72 years old & 44 & $22(50.0)$ & $1.30(0.51-3.32)$ & 0.573 & $35(79.5)$ & $0.97(0.30-3.09)$ & 0.962 & $23(52.3)$ & $1.09(0.43-2.77)$ & 0.848 \\
\hline \multicolumn{11}{|l|}{ Marital status } \\
\hline No partner & 40 & $17(42.5)$ & 1.0 & & $30(75.0)$ & 1.0 & & $18(45.0)$ & 1.0 & \\
\hline With partner & 34 & $18(52.9)$ & $1.52(0.60-3.81)$ & 0.370 & $29(85.3)$ & $1.93(0.58-6.34)$ & 0.272 & $20(58.8)$ & $1.74(0.69-4.40)$ & 0.236 \\
\hline \multicolumn{11}{|l|}{ Children ( $\leq 6$ years) } \\
\hline No & 65 & $30(46.2)$ & 1.0 & & $51(78.5)$ & 1.0 & & $35(53.8)$ & 1.0 & \\
\hline Yes & 09 & $05(55.6)$ & $1.45(0.35-5.92)$ & 0.430 & 08(88.9) & $2.19(0.25-19.06)$ & 0.415 & 03(33.3) & $0.42(0.09-1.86)$ & 0.213 \\
\hline \multicolumn{11}{|l|}{ Category } \\
\hline Nurse & 14 & $06(42.9)$ & 1.0 & & $11(78.6)$ & 1.0 & & $05(35.7)$ & 1.0 & \\
\hline Assistant/technician & 60 & $29(48.3)$ & $1.24(0.38-4.03)$ & 0.712 & $48(80.0)$ & $1.09(0.26-4.53)$ & 0.580 & $33(55.0)$ & $2.20(0.65-7.34)$ & 0.158 \\
\hline \multicolumn{11}{|l|}{ Work hours } \\
\hline$\leq 30$ hours per week & 52 & $22(42.3)$ & 1.0 & & $40(76.9)$ & 1.0 & & $23(44.2)$ & 1.0 & \\
\hline$>30$ hours per week & 22 & 13(59.1) & $1.97(0.71-5.42)$ & 0.186 & 19(86.4) & $1.90(0.47-7.53)$ & 0.278 & $15(68.2)$ & $2.70(0.94-7.72)$ & 0.060 \\
\hline \multicolumn{11}{|l|}{ Number of jobs } \\
\hline Just one & 40 & $22(55.0)$ & 1.0 & & $30(75.0)$ & 1.0 & & $21(52.5)$ & 1.0 & \\
\hline Two or more & 34 & 13(38.2) & $0.50(0.20-1.28)$ & 0.150 & $29(85.3)$ & $1.93(0.58-6.34)$ & 0.272 & $17(50.0)$ & $0.90(0.36-2.25)$ & 0.830 \\
\hline \multicolumn{11}{|l|}{ Night shift } \\
\hline No & 32 & $13(40.6)$ & 1.0 & & $24(75.0)$ & 1.0 & & $12(37.5)$ & 1.0 & \\
\hline Yes & 42 & $22(52.4)$ & $1.60(0.63-4.07)$ & 0.316 & $35(83.3)$ & $1.66(0.53-5.20)$ & 0.377 & $26(61.9)$ & $2.70(1.05-6.99)$ & 0.037 \\
\hline \multicolumn{11}{|l|}{ Physical activity } \\
\hline Yes & 42 & $19(45.2)$ & 1.0 & & $35(83.3)$ & 1.0 & & $22(52.4)$ & 1.0 & \\
\hline No & 23 & $16(50.0)$ & $1.21(0.48-3.04)$ & 0.684 & $24(75.0)$ & $0.60(0.19-1.87)$ & 0.377 & $16(50.0)$ & $0.90(0.36-2.28)$ & 0.839 \\
\hline \multicolumn{11}{|l|}{ Leisure time } \\
\hline Yes & 58 & $27(46.6)$ & 1.0 & & $44(75.9)$ & 1.0 & & $27(46.6)$ & 1.0 & \\
\hline No & 16 & $08(50.0)$ & $1.14(0.37-3.47)$ & 0.807 & 15(93.8) & $4.77(0.57-39.43)$ & 0.105 & $11(68.8)$ & $2.52(0.77-8.19)$ & 0.116 \\
\hline \multicolumn{11}{|l|}{ Health problems } \\
\hline Three diagnostics & 55 & $26(47.3)$ & 1.0 & & $42(76.4)$ & 1.0 & & $28(50.9)$ & 1.0 & \\
\hline$\geq 4$ diagnostics & 19 & $09(47.4)$ & $1.00(0.35-2.85)$ & 0.994 & $17(89.5)$ & $2.63(0.53-12.92)$ & 0.188 & $10(52.6)$ & $1.07(0.37-3.04)$ & 0.555 \\
\hline \multicolumn{11}{|l|}{ Insomnia complaints } \\
\hline No & 49 & $21(42.9)$ & 1.0 & & $36(73.5)$ & 1.0 & & $21(42.9)$ & 1.0 & \\
\hline Yes & 25 & $14(56.0)$ & $1.69(0.64-4.48)$ & 0.284 & $23(92.0)$ & $4.15(0.85-20.12)$ & 0.061 & $17(68.0)$ & $2.83(1.02-7.80)$ & 0.041 \\
\hline
\end{tabular}

\section{Discussion}

The sociodemographic characteristics of the sample are similar to those found in other studies ${ }^{(14-15)}$, reinforcing the profile of the Brazilian nursing workforce with a predominance of female and adultyoung professionals.
The participants in this study were in risk of illness fundamentally associated with the work context. Our findings confirm the vulnerability of the nursing staff to illness due to stressors in the work environment, such as physical and psychological demands, repetition of tasks, pressures and responsibilities, need for constant attention, ergonomic risks, manipulation of materials 
with risk of exposure to contaminated fluids, wage dissatisfaction and non-recognition by peers ${ }^{(14)}$.

In this study, referrals to insomnia are associated with the risk of illness both for socio-professional relationships and for physical costs. In this regard, a study proved that the nursing staff of psychiatric hospitals recognizes more the risks to their physical health than to the psychic, denoting an arduous and dangerous work. It also reinforced the need to expand the scope of knowledge of workers about what constitutes risk to their health, considering that less than half of the study sample communicated its last exposure to some occupational risk to the management bodies of hospitals ${ }^{(16)}$.

Previous studies demonstrated that sleep disorders were reported by workers with Burnout ${ }^{(17)}$, even though there was an association between insomnia and musculoskeletal disorders - such as headaches, back and neck pain ${ }^{(18)}$ - and that the number of nursing professionals who attend work complaining of some musculoskeletal symptom is considerable(19). Some studies $^{(14,18-20)}$ have indicated that the main body sites of musculoskeletal disorders are the regions of the head and cervical, lumbar and thoracic spine.

Thus, insomnia associated with the risk of illness for physical cost represents an occupational health problem that usually has multifactorial causality, including the physical, psychosocial and ergonomic dimensions.

In addition, it is noteworthy that sleep dissatisfaction was associated with patterns of negative and sometimes "cynical" attitudes and feelings, reinforcing the findings of this research(21). In this line, it is important to point out that social support, professional recognition by patients, superiors and other team members, optimism, pleasure and job satisfaction are protective factors for not getting sick and cordiality and respect relationships should be strengthened(22).

The study also measured the association between night work and the dimensions of risk of illness, and it was found that it is approximately three times more likely to present risk of illness for physical cost among night shift workers than those who works during the day. Literature data corroborate the findings of this investigation, identifying that working at night increases the risk of depersonalization(22), with higher prevalence of mood swings and headaches among night workers ${ }^{(23)}$. After night work, the risk of headaches and upper limbs increased; when associated with a few hours of sleep, it also increases the risk of abdominal and back pain. (24).

Despite having lower labor demands and higher financial gains - considering the additional wages in relation to daytime workers -, nursing professionals in the night shift have a fragmented work process with interpersonal relationships often conflicting and/or absent, due to low supervision and lower staff numbers, which can cause social isolation and physical and mental illness ${ }^{(21)}$.

Thus, the importance of the balance between private and professional life is outlined and also the importance of avoiding dissonances between the chronotype and the work shift, thus minimizing biological disorders, the commitment of professional performance and social and family relationships ${ }^{(25)}$.

Given the findings presented here - greater chances of risk of illness related to physical cost among those workers who work at night and reported complaints of insomnia -, it is pointed out the possibility of the amount of hours of sleep act as a mediator between the work shift and the risk of illness, corroborating a previous study ${ }^{(24)}$

Although this investigation did not find a significant difference in the odds ratio between the different working days, the study showed higher prevalence of illness among workers with long working hours(26). The illness resulting from long working days can be explained by the reduction of free time - for sleep and recovery, family and social experience in addition to the longer exposure time to the risks of illness limited to the work environment ${ }^{(27)}$. This aspect was reported by nurses in qualitative research, when they attributed the illness to work overload and lack of time for self-care(28).

Nursing still appears as the professional category that performs the longest working day among health care professionals(29). A study revealed that, despite positively understanding their work as a care relationship, nursing workers recognize the deficiencies and deficits associated with the organization and working conditions - such as work overload, lack of autonomy and deficit of staff and material -, thus pointing to an ambivalent work ${ }^{(30)}$. It is important to highlight that long working days were associated with inadequate working conditions, work overload and stress ${ }^{(31)}$.

A study pointed out that the reduction of the workday makes the work more pleasant, with improved recovery, lower energy requirements, improvements in the quality of care and promotion of balance between personal and professional life $^{(32)}$. These results are consistent with the current debates in favor of reducing the weekly working hours, considering that this factor is characterized as a systemic stressor, representing a serious and challenging occupational health problem.

Although there was no significant reference - in this research - to the impact on the psychic sphere (affective 
and cognitive cost) of the individuals interviewed, the work within psychiatric hospitals has great potential to affect their emotional stability.

In addition to acute situations or psychotic outbreaks, which place all workers in psychiatric institutions in a constant state of alert and emotional tension, patients in a psychiatric institution are individuals stigmatized by society and are in the process of rehabilitation. The nursing team, being the one that most have contact with these individuals - being, therefore, more time in a face to face relationship with the suffering of patients -, deals with chronic events, whose horizon or perspective of improvement or cure is slow, perhaps, distant. This reality may translate into frustration for the nursing team, which usually does not see the return of their effort and commitment.

Working in an environment without the proper structure, without the recognition and appreciation of colleagues who share the work environment, together with low wages and long working hours, are also factors that negatively affect the health of these workers, making them more vulnerable to illness. On the other hand, factors such as social recognition, good work relations, good pay and fair working hours act as protective elements should be reinforced to avoid illness.

The strengthening of the set of knowledge of nursing workers about what may constitute a real risk to their health, using in-service education actions, should also be considered. Once clarified about the different kinds of risks to which they are exposed in their work environment, this nursing worker can create strategies to minimize the different risks to their health, not only physically, but also emotionally.

The results of this study, however, alert us to think about solutions for night shift workers that are usually outside the scope of in-service education initiatives. In other words, educational actions are generally designed and implemented for day shift workers. This "isolation/distancing" from the other members of the nursing team can lead to a feeling of "not being part" of the group, further removing the night shift worker from the feeling of being part of a team that works collaboratively aimed at the recovery of the individual with mental health problems.

The limitations of the study are due to the size of the sample and its design, because, despite meeting the proposed objectives, 74 nursing professionals in the hospital area do not standardize the nursing context in psychiatry existing in Brazil, and make it impossible to perform more elaborate statistical analyses, besides not being possible to make causal inferences.

\section{Conclusion}

The results confirmed associations between insomnia complaints, night work and working days of more than 30 hours per week and the risks of illness, mainly associated with the work context. Thus, we concluded that there is evidence that the associations between the work variables, health conditions and life habits and the risks of illness related to the dimensions of the context and human cost at work can harm the health of the nursing staff working in a psychiatric hospital. Thus, this study will greatly contribute to the knowledge of the risk factors that generate illness of professionals and more specifically the intensity and perception of these factors by professionals, in the context of work in the psychiatric nursing area.

\section{References}

1. Andrade APM, Maluf SW. Subjects and (in) experience: micropolitical strategies in the context of the psychiatric reform in Brazil. Physis. 2016; 26(1):251-70. doi: http://doi.org/10.1590/S0103-73312016000100014

2. Macedo JP, Abreu MM, Fontenele MG, Dimenstein M. The regionalization of mental health and new challenges of the Psychiatric Reform in Brazil. Saúde Soc. 2017;26(1):155-70. doi: http://doi.org/10.1590/ S0104-12902017165827

3. Moura GA, Roncalli AG, Noro LRA. Work impact on professionals from mental health services in a Brazilian northeast city. Psicol Cien Prof. 2016;36(2):401-10. doi: http://doi.org/10.1590/1982-3703000342014

4. Souza SRC, Oliveira EB, Mauro MYC, Mello R, Kestenberg CCF, Paula GS. Nursing workload in a psychiatric inpatient unit and workers' health. Rev Enferm UERJ. 2015;23(5):633-8. doi: http://doi.org/ 10.12957/reuerj.2015.19563

5. Pekurinen V, Willman L, Virtanen $M$, Kivimäki $M$, Vahtera J, Välimäki M. Patient aggression and the wellbeing of nurses: a cross-sectional survey study in psychiatric and non-psychiatric settings. Int J Environ Res Public Health. 2017;14(1245):2-14. doi: http://doi.org/ 10.3390/ijerph14101245

6. Sousa KHJF, Gonçalves TS, Silva MB, Soares ECF, Nogueira MLF, Zeitoune RCG. Risks of illness in the work of the nursing team in a psychiatric hospital. Rev. Latino-Am. Enfermagem. 2018;26:e3032.doi: http:// doi.org/10.1590/1518-8345.2458.3032

7. Sousa KHJF, Lopes DP, Nogueira MLF, Tracera GMP, Moraes KG, Zeitoune RCG. Risk of illness and human cost at work in a psychiatric hospital. Esc Anna Nery. 2018;22(2):e20170288. doi: http://doi.org/ 10.1590/2177-9465-ean-2017-0288 
8. Silva RM, Zeitoune RCG, Beck CLC, Souza SBC, Santos E. Chronotype and work accidents in the nursing team of a surgical clinic. Texto Contexto Enferm. 2015;24(1):245-52. doi: http://doi.org/10.1590/010407072015003420013

9. Merchaoui I, Bouzgarrou L, Mnasri A, Mghanem M, Ajrout $M$, Malchaire $J$, et al. Influence of shift work on the physical work capacity of Tunisian nurses:a crosssectional study in two university hospitals. Pan African Med J. [Internet]. 2017[cited Feb 27, 2019];26:59. Available from: http://www.panafrican-med-journal. com/content/article/26/59/full/

10. Vieira GLC. Satisfaction and workload among nursing techniciansinpsychiatrichospitals. RPESM. 2017;(17):43-9. doi: http://doi.org/10.19131/rpesm.0182

11. Brolese DF, Lessa G, Santos JLG, Mendes JS, Cunha KS, Rodrigues J. Resilience of the health in caring for people with mental disorders in a psychiatric hospital. Rev Esc Enferm USP. 2017;51:03230. doi: http://doi. org/10.1590/s1980-220×2016026003230

12. Stimpfel AW, Sloane DM, Aiken LH. The longer the shifts for hospital nurses, the higher the levels of burnout and patient dissatisfaction. Health Aff. 2012;31(11):2501-9. doi: http://doi.org/10.1377/ hlthaff. 2011.1377

13. Mendes AM, Ferreira MC. Inventário sobre Trabalho e Riscos de Adoecimento - ITRA: instrumento auxiliar de diagnóstico de indicadores críticos no trabalho. In: Mendes AM, organizador. Psicodinâmica do Trabalho: teoria, método e pesquisas. São Paulo: Casa do Psicólogo; 2007. p. 111-25.

14. Silva TPD, Araújo WN, Stival MM, Toledo AM, BurkeTN, Carregaro RL. Musculo skeletal discomfort, work ability and fatigue in nursing professional working in a hospital environment. Rev Esc Enferm USP. 2018; 52:e03332. doi: http://doi.org/10.1590/S1980-220X2017022903332

15. Santana LL, Sarquis LMM, Miranda FMA, Kalinke LP, Felli VEA, Miniel VA. Health indicators of workers of the hospital area. Rev Bras Enferm. 2016;69(1):23-32. doi: http://doi.org/10.1590/0034-7167.2016690104i

16. Alhassan RK, Poku KA. Experiences of frontline nursing staff on workplace safety and occupational health hazards in two psychiatric hospitals in Ghana. BMC Public Health. 2018;18:701. doi: http://doi.org/ 10.1186/s12889-018-5620-5

17. Portela LF, Kröning Luna C, Rotenberg L, SilvaCosta A, Toivanen S, Araújo T, et al. Job strain and selfreported insomnia symptoms among nurses: what about the influence of emotional demands and social support? Biomed Res Int. 2015;2015:820610. doi: http://doi. org/10.1155/2015/820610

18. Katsifaraki M, Nilsen KB, Waersted M, Knardahl S, Lie JAS, Bjorvatn B, et al. The association of sleepiness, insomnia, sleepdisturbanceand pain: astudyamongstshift working nurses. Sleep Biol Rhythms. 2018;16:133-40. doi: http://doi.org/10.1007/s41105-017-0135-5

19. Santos HEC, Marziale MHP, Felli VEA. Presenteeism and musculoskeletal symptoms among nursing professionals. Rev. Latino-Am. Enfermagem. 2018;26:e3006. doi: http://doi.org/10.1590/1518-8345.2185.3006

20. Luan HD, Hai NT, Xanh PT, Giang HT, Thuc PV, Hong NM, et al. Musculoskeletal disorders: prevalence and associated factors among district hospital nurses in Haiphong, Vietnam. Bio Med Res Int. 2018;(2):[9 pages]. doi: http://doi.org/10.1155/2018/3162564

21. Vidotti V, Ribeiro RP, Galdino MJQ, Martins JT. Burnout Syndrome and shift work among the nursing staff. Rev. Latino-Am. Enfermagem. 2018;26:e3022. doi: http://doi.org/10.1590/1518-8345.2550.3022

22. Merino-Plaza MJ, Carrera-Hueso FX, Arribas-Boscá N, Martínez-Asensi A, Vázquez-Ferreiro $P$, VargasMorales $A$, et al. Staff burnout and psychosocial risk factors in a long-stay hospital in Spain. Cad Saúde Pública. 2018;34(11):e00189217. doi: http://doi.org/ 10.1590/0102-311X00189217

23. Jensen HI, Larsen JW, Thomsen TD. The impact of shift work on intensive care nurses' live soutside work: a cross-sectional study. J Clin Nurs. 2018;27:e703-e709. doi: http://doi.org/10.1111/jocn.14197

24. Katsifaraki M, Nilsen KB, Christensen JO, Waersted M, Knardahl S, Bjorvatn B, et al. Sleep duration mediates abdominal and lower-extremity pain after night work in nurses. Int Arch Occup Environ Health. 2018;1-8. doi: http://doi.org/10.1007/s00420-018-1373-9

25. Silva RM, Zeitoune RCG, Beck CLC, Martino MMF, Prestes FC, Loro MM. Chronotype and work shift in nursing workers of university hospitals. Rev Bras Enferm. 2017;70(5):958-64. doi: http://doi.org/10.1590/00347167-2016-0542

26. Lee JG, Kim GH, Jung SW, Kim SW, Lee JH, Lee KJ. The association between long working hours and work-related musculoskeletal symptoms of Korean wageworkers: data from the fourth Korean working conditions survey (a cross-sectional study). Annals Occup Environ Med. 2018;30:67. doi: http://doi. org/10.1186/s40557-018-0278-0

27. Fernandes JC, Portela LF, Griep RH, Rotenberg L. Working hours and health in nurses of public hospitals according to gender. Rev Saúde Pública. 2017;51:63. doi: http://doi.org/10.1590/S1518-8787.2017051006808

28. Pereira AV. Nurses' daily life: gender relations from the time spent in hospital. Rev. Latino-Am. Enfermagem. 2015;23(5):945-53. doi: http://doi.org/10.1590/01041169.0485 .2635

29. Oliveira BLCA, Silva AM, Lima SF. Weekly workload for nurses in brazil: challenges to practice the profession. 
Trab Educ Saúde. 2018;16(3):1221-36. doi: http://doi. org/10.1590/1981-7746-sol00159

30. Granero A, Blanch JM, Ochoa P. Labor conditions and the meanings of nursing work in Barcelona. Rev. Latino-Am. Enfermagem. 2018;26:e2947. doi: http:// doi.org/10.1590/1518-8345.2342.2947

31. Lala AI, Sturzu LM, Picard JP, Druot F, Grama F, Bobirnac G. Coping behaviour and risk and resilience stress factors in French regional emergency medicine unit workers: a cross-sectional survey. J Med Life. [Internet]. 2016[cited Feb 27, 2019];9(4):363-8. Available from: https://www.ncbi.nlm.nih.gov/pmc/ articles/PMC5141395/

32. Gyllensten K, Andersson G, Muller H. Experiences of reduced work hours for nurses and assistant nurses at a surgical department: a qualitative study. BMC Nurs. 2017;16:16. doi: http://doi.org/10.1186/

s12912-017-0210-x Creative Commons (CC BY).

This license lets others distribute, remix, tweak, and build upon your work, even commercially, as long as they credit you for the original creation. This is the most accommodating of licenses offered. Recommended for maximum dissemination and use of licensed materials. 